\title{
Nano Materials for Early Detection of Cancer
}

\author{
Biran Wang* \\ Department of Industrial \& Systems Engineering, Texas A \& M University, USA
}

Submission: March 27, 2017; Published:April 24, 2017

*Corresponding author: Biran Wang, Department of Industrial \& Systems Engineering, Texas A\&M University, USA;

Tel: +1-979-458-2371; Fax: +1-979-458-4299; Email: bwang0416@tamu.edu

\begin{abstract}
Cancer is one of the leading causes of morbidity and mortality worldwide, more than 600000 people die annually in the US along. In reality, no matter what kind of cancer, the survival rate is much higher and the expense is much lower for people diagnosed with early stage cancer than with later stage cancer. However, current clinical techniques are difficult to detect cancer in the early stage, due to their small size and the fact that they are hidden very deep. Nano materials provide incredible properties, such as high relative surface area, quantum confinement, etc., which have been largely used for early detection. This mini review gives a simple overview of current progress in the field of nano materials for early detection of cancer.
\end{abstract}

Keywords: Nano materials; Early detection; Cancer; Liquid biopsy; CTCs; Exosome; CtDNA; MiRNA

\section{Introduction}

According to the American Cancer Society, 600,920 cancer deaths are projected to occur in the United States in 2017 [1]. This number could be much lower if the cancer patients early. This same report showed that for the 4 major cancers (lung, breast, prostate, and colorectum), the 5-year survival rates are 55\%, 99\%, 99\% and 90\% for the patients diagnosed with localized disease, compare to $4 \%, 26 \%, 29 \%$ and $14 \%$ for people who diagnosed with distant stage disease, as showed in Figure 1.

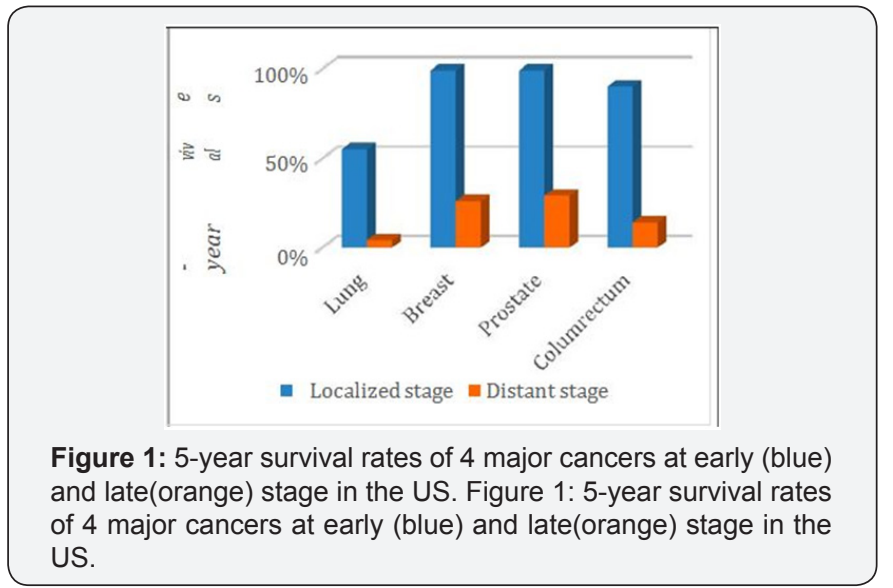

Early detection of cancer greatly increases the chances for successful treatment. However, currently, screening tests seem to be the only available clinical techniques to find cancer. General speaking, there is three types of screening tests: Imaging tests (CT, MRI, etc.), Endoscopy procedures and biopsy \& cytology tests. Those tests are not only painful and expensive, but also difficult to find out tumor smaller than $1 \mathrm{~cm}$ in diameter due to insufficient sensitivity [2], which means they are difficult to detect the early stage cancer

In this context, a patient-friendly approach called liquid biopsy could become the standard diagnostic tool for cancer diagnosis. Liquid biopsy is an analysis of biomarkers including circulating tumor cells (CTC) [3], circulating tumor DNA (CtDNA) $[4,5]$ and exosomes [6] released into the peripheral blood from metastatic deposits. Researchers use variable techniques to detect and enrich those biomarkers. Due to the unique optical, chemical, mechanical and magnetic properties, nano materials have been broadly used for biomarker detection in liquid biopsy. Nano materials that have been reported vary from gold nano particles, quantum dots, magnetic nano particles, carbon nano tubes and nano wires. This mini review will cover recent developments in early detection of cancer using nano materials with an emphasis on the studies focusing on detection of biomarkers in liquid biopsy using nano materials.

\section{Discussion}

According to the difference of the size and the number of biomarkers in the liquid biopsy, as in Table 1, various nano materials and detective techniques have been applied, and they have a similar primary goal to separate or to isolate biomarkers from their interferences. 
Table 1: The size and concentration of biomarkers (dark) and regular component in blood sample.

\begin{tabular}{|c|c|c|}
\hline Blood samples & Size range & N per mL \\
\hline CTCs & $10-20 \mu \mathrm{m}$ & 10 \\
\hline Red blood cell & $6-8 \mu \mathrm{m}$ & $10^{9}$ \\
\hline White blood cell & $12-15 \mu \mathrm{m}$ & $10^{11}$ \\
\hline Normal Exosome & $30-100 \mathrm{~nm}$ & $10^{9}$ \\
\hline Tumor Exosome & $30-100 \mathrm{~nm}$ & $10^{9}$ \\
\hline Cell-free normal DNA & $150-200 \mathrm{bp}$ & $10^{5}-10^{7}$ \\
\hline CtDNA & $150-200+\mathrm{bp}$ & $10^{9}$ \\
\hline Circulating miRNA & $19-23 \mathrm{bp}$ & \\
\hline
\end{tabular}

Modern cancer research firstly started to investigate CTC as liquid biopsy began in the mid-1990s, due to its obvious bigger size compare to the other biomarkers. However, the capture of CTCs is quite challenging owing to its rare number in the blood. To increase the sensitivity and specificity, the recent CTCs detection approaches tend to use dual-targeting strategy. Yao et al. [7] integrated tumor neovessels-targetable ligands K237 peptide with Ep23 aptamer against epithelial cell adhesion molecule (EpCAM) into a paclitaxel (PTX)-loaded biodegradable polymer nano particles as the model drug, aiming at damaging the primary tumor and neutralizing CTCs simultaneously to achieve a synergistic anti-tumor therapeutic effect. Lou et al. [8] introduced a dual-functional lipid coating on quartz nanopillar arrays, anti-EpCAM, and anti-EGFR. The lipid coating serves both as an effective passivation layer that helps prevent nonspecific cell adhesion and as a functionalized layer for antibody-based specific cell capture. The magnetic nano particle has largely used in cancer research $[9,10]$, Hong et al. [11] developed the multifunctional magnetic nano wires, which are equipped with a high density of magnetic nano particles and five different types of antibodies, offer a significant improvement in cell isolation efficiency, even from very small amounts of blood. The major issues about the biological approach to isolate CTCs are heterogeneity and surface antigen expression changes during the process of epithelial-mesenchymal transition (EMT) [12]. Therefore, label-free isolation based on physical properties of CTCs has been developed. Recently, some studies showed that based on geometries and dimensions of nano structured surface, without antibody conjugation, the CTCs capture efficiency have been improved $[13,14]$.

Exosomes are small sized extracellular vesicles that contain various molecular constituents of their cell of origin, including proteins, RNA and DNA. They play a crucial role in cell to cell communication and provide an exclusive approach for drug delivery [15] and early detection of cancer. The differential ultracentrifugation (DC) has been widely used as conventional isolation techniques that separate exosomes [16], however, it has several disadvantages, such as labor and time consuming, low recovery yield, low specificity, etc. Recently, Lm et al. [17] developed a label-free, high-throughput nano-plasmonic Exosome (nPLEX) platform to capture Exosome. They showed that this approach offers improved sensitivity. Zhou et al. [18] carried a chip-based approach for electrochemical characterization and detection of exosomes, which based on direct electro-oxidation of metal nano particles (MNPs) that specifically recognize surface markers of the Exosome. They also showed that Exosome can be identified by their surface proteins, and suggesting the potential of exosomes for diagnostics (Table 1).

With the recent advances in sequencing technology, CtDNA becomes a new generation of cancer biomarkers, it's the fragmented DNA released by dying tumor cells in the blood. The amounts of CtDNA are extremely low and variable, barely $1-0.01 \%$ of the total circulating DNA in blood [19]. This fact makes detection of CtDNA very difficult, currently, there doesn't exist a standardized method for CtDNA detection, and the CtDNA analysis is not currently used in routine clinical procedures. To improve CtDNA detection sensitivity and specificity, many efforts have been made, and nano materials have become a popular platform due to its unique properties. Das et al. [20] functionalized nano structured microelectrodes with PNA probes specific to a specific mutant DNA sequence, and a series of PNA clamps were used to achieve high specificity so that the sensors could differentiate mutated DNA sequence from wildtype DNA sequence and other similar mutant sequence. Prior to that, Huang et al. [21] developed a simple and ultrasensitive electrochemical DNA bio sensing nano-platform through integrating MoS2/multi-walled carbon nano tube composites and gold nano particle (AuNP)- modified electrode signal amplification with enzymatic signal readout, they achieved subfemtomolar DNA detection.

Circulating miRNAs have emerged as a new class of promising cancer biomarkers with remarkable stability [22], it is considered as an ideal biomarker for cancer detection in early stages. Nano materials have been intensively studied, including metal nano materials [23], quantum dots (QDs) [24], graphene oxide (GO) [25] and silicon nano particles [26]. Wen et al. [27] developed an ultrasensitive DNA nanostructure-based electrochemical miRNA biosensor, which can directly detect as few as attomolar $(<1000$ copies) miRNAs with high single-base discrimination ability. Mao et al. [28] developed a simpler method for miRNA detection based on base stacking hybridization happening on the surface of NaYF4: Yb, Er up conversion nano particles.

\section{Conclusion}

There is an urgent demand for finding a way to precisely detect cancer in its early stage. Nano materials have their own 
extraordinary properties; provide the promising potential for this mission. This mini review summarized recent developments in early detection of cancer using various nano materials as biosensors, with great specificity and sensitivity that is revolutionizing the early detection field. Among the four main biomarkers: CTCs, Exosome, CtDNA and circulating miRNA, CTCs and CtDNA are relatively better investigated, they need to be standardized. Exosome and cell-free microRNA as a promising analyst of liquid biopsy should be further explored and validated. In conclusion, the liquid biopsy could become a clinical standard and benefits millions of cancer patients in the near future.

\section{Refernces}

1. Siegel RL, Miller KD, Jemal A (2017) Cancer statistics, 2017. CA Cancer J Clin 67(1): 7-30.

2. Sree SV, Ng EY, Acharya RU, Faust $O$ (2011) Breast imaging: A survey. World J Clin Oncol 2(4): 171-178.

3. Scher HI, Jia X, de Bono JS, Fleisher M, Pienta KJ, et al. (2009) Circulating tumour cells as prognostic markers in progressive, castration-resistant prostate cancer: a reanalysis of IMMC38 trial data. Lancet Oncol 10(3): 233-239.

4. Dawson SJ, Tsui DW, Murtaza M, Biggs H, Rueda OM, et al. (2013) Analysis of Circulating Tumor DNA to Monitor Metastatic Breast Cancer. N Engl J Med 368(13): 199-1209.

5. Murtaza M, Dawson SJ, Tsui DW, Gale D, Forshew T, et al. (2013) Non-invasive analysis of acquired resistance to cancer therapy by sequencing of plasma DNA. Nature 497(7447): 108-112.

6. Peinado H, Alečković M, Lavotshkin S, Matei I, Costa-SB, et al. (2012) Melanoma exosomes educate bone marrow progenitor cells toward a pro-metastatic phenotype through MET. Nat Med 18(6): 883-891.

7. Yao J, Feng J, Gao X, Wei D, Kang T, et al. (2017) Neovasculature and circulating tumor cells dual-targeting nanoparticles for the treatment of the highly-invasive breast cancer. Biomaterials 113: 1-17.

8. Lou HY, Zhao W, Hanson L, Zeng C, Cui Y, et al. (2017) Dual-Functional Lipid Coating for the Nanopillar-Based Capture of Circulating Tumor Cells with High Purity and Efficiency. Langmuir 33(4): 1097-1104.

9. Biran W, Céline B, Juan M-G, Pascal L, Alexandra M, et al. (2013) Necrosis of HepG2 cancer cells induced by the vibration of magnetic particles. J Magn Magn Mater 344: 193-201.

10. Juan M-G, Biran W, Alexandra M, Christophe DG, Georges B, et al. (2013) Synthesis and Surface Modification of Spindle-Type Magnetic Nano particles: Gold Coating and PEG Functionalization. J Biomater Nano biotechnology 4: 222-228.

11. Hong W, Lee S, Chang HJ, Lee ES, Cho Y, et al. (2016) Multifunctional magnetic nano wires: A novel breakthrough for ultrasensitive detection and isolation of rare cancer cells from non-metastatic early breast cancer patients using small volumes of blood. Biomaterials 106: 78-86.

12. Yu M, Bardia A, Wittner BS, Stott SL, Smas ME, et al. (2013) Circulating Breast Tumor Cells Exhibit Dynamic Changes in Epithelial and Mesenchymal Composition. Science 339(6119): 580-584.
13. Shi L, Wang K, Yang Y (2016) Adhesion-based tumor cell capture using nanotopography. Colloids Surf B Biointerfaces 147: 291-299.

14. Chen W, Weng S, Zhang F, Allen S, Li X, et al. (2013) Nanoroughened Surfaces for Efficient Capture of Circulating Tumor Cells without Using Capture Antibodies. ACS Nano 7(1): 566-575.

15. Batrakova EV, Kim MS (2015) Using exosomes, naturally-equipped nanocarriers, for drug delivery. J Controlled Release 219: 396-405.

16. Soung Y, Ford S, Zhang V, Chung J (2017) Exosomes in Cancer Diagnostics Cancers (Basel) 9(1): pii: E8.

17. Im H, Shao H, Park YI, Peterson VM, Castro CM, et al. (2014) Label-free detection and molecular profiling of exosomes with a nano-plasmonic sensor. Nat Biotechnol 32(5): 490-495.

18. Zhou YG, Mohamadi RM, Poudineh M, Kermanshah L, Ahmed S, et al. (2016) Interrogating Circulating Microsomes and Exosomes Using Metal Nanoparticles. Small 12(7): 727-732.

19. Yong E (2014) Cancer biomarkers: Written in blood. Nature 511(7511): 524-526.

20. Das J, Ivanov I, Sargent EH, Kelley SO (2016) DNA Clutch Probes for Circulating Tumor DNA Analysis. J Am Chem Soc 138(34): 1100911016.

21. Huang KJ, Liu YJ, Wang HB, Wang YY, Liu YM (2014) Sub-femtomolar DNA detection based on layered molybdenum disulfide/multi-walled carbon nanotube composites, Au nanoparticle and enzyme multiple signal amplification. Biosens Bioelectron 55: 195-202.

22. Mitchell PS, Parkin RK, Kroh EM, Fritz BR, Wyman SK, et al. (2008) Circulating microRNAs as stable blood-based markers for cancer detection. Proc Natl Acad Sci USA 105(30): 10513-10518.

23. Ito H, Hasegawa K, Hasegawa Y, Nishimaki T, Hosomichi K, et al (2015) Silver Nanoscale Hexagonal Column Chips for Detecting Cell-free DNA and Circulating Nucleosomes in Cancer Patients. Sci Rep 5: 10455.

24. Qiu X, Hildebrandt N (2015) Rapid and Multiplexed MicroRNA Diagnostic Assay Using Quantum Dot-Based Förster Resonance Energy Transfer. ACS Nano 9(8): 8449-8457.

25. Azimzadeh M, Rahaie M, Nasirizadeh N, Ashtari K, Naderi-MH (2016) An electrochemical nanobiosensor for plasma miRNA-155, based on graphene oxide and gold nanorod, for early detection of breast cancer. Biosens Bioelectron 77: 99-106.

26. Su X, Kuang L, Battle C, Shaner T, Mitchell BS, et al. (2014) Mild TwoStep Method to Construct DNA-Conjugated Silicon Nanoparticles: Scaffolds for the Detection of MicroRNA-21. Bioconjug Chem 25(10): 1739-1743.

27. Yanli W, Gang L, Hao P, Lanying L, Qin X, et al. (2013) DNA nanostructurebased ultrasensitive electrochemical microRNA biosensor. Methods 64(3): 276-282.

28. Mao L, Lu Z, He N, et al. (2017) A new method for improving the accuracy of miRNA detection with NaYF4: Yb, Er up conversion nanoparticle. SCIENCE CHINA Chemistry 60(1): 157-162. 
This work is licensed under Creative Commons Attribution 4.0 Licens

DOI: 10.19080/JOJMS.2017.01.555555
Your next submission with Juniper Publishers will reach you the below assets

- Quality Editorial service

- Swift Peer Review

- Reprints availability

- E-prints Service

- Manuscript Podcast for convenient understanding

- Global attainment for your research

- Manuscript accessibility in different formats ( Pdf, E-pub, Full Text, Audio)

- Unceasing customer service

Track the below URL for one-step submission https://juniperpublishers.com/online-submission.php 